\title{
Electroforesis en Gel de Campo Pulsado (PFGE) para la diferenciación molecular de Listeria monocytogenes
}

\author{
Ángela María Cardozo-Bernal ${ }^{1}$, Luisa Fernanda Ramón ${ }^{2}$, Raúl A. Poutou-Piñales ${ }^{1 凹}$, \\ Ana K. Carrascal-Camacho' ${ }^{2}$ Diana Corina Zambrano ${ }^{3}$
}

Pulsed-field gel electrophoresis (PFGE) for the molecular differentiation of Listeria monocytogenes

Abstract

The reporting of $L$. monocytogenes in food in Colombia is not a mandatory; however, foods considered high-risk are monitored, and the organism is only reported clinically as Gram-positive when it causes meningitis. L. monocytogenes is a foodborne, intracellular, pathogen which causes listeriosis, a disease lethal to humans and animals. Outbreaks of this disease worldwide can bring about human and economic losses. Only a few studies in Colombia have been able to identify and molecularly serotype isolates allowing only the theoretical distribution of serotypes by lineage. This review explains the characteristics of the pathogen, its importance in public health and in the food industry, and provides an overview of PFGE-CHEF; identifying the standard work protocol and the appropriate restriction enzymes to cut DNA. We found that the enzyme combination, $X b a \mathrm{I}-A s c \mathrm{I}$, followed by $A p a \mathrm{I}$ offers the best results to differentiate isolates, by grouping them by lineages, and displaying intra-serotype variations. Additionally, we found that in several Latin American countries the results are analyzed using PulseNet; this ensures the comparison of PFGE patterns in equivalent conditions.

Keywords: Molecular typing; Lineages; Serotypes; Listeria.

\section{Edited by Alberto Acosta}

1 Laboratorio de Biotecnología Molecular.

2 Laboratorio de Microbiología de Alimentos. Grupo de Biotecnología Ambiental e Industrial (GBAI). Departamento de Microbiología.

Facultad de Ciencias. Pontificia Universidad Javeriana, Bogotá, D.C., Colombia.

3 Dirección de Investigación y Transferencia de Tecnología, Asociación Colombiana de Porcicultores-FNP-CENIPORCINO, Bogotá, D.C., Colombia.

Received: 25-07-2013 Accepted: 27-08-2013

Published on line: 30-08-2013

Citation: Cardozo-Bernal AM, Ramón LF, Poutou-Piñales RA, Carrascal-Camacho AK, Zambrano DC (2013) Electroforesis en Gel de Campo Pulsado (PFGE) para la diferenciación molecular de Listeria monocytogenes. Universitas Scientiarum 18(2): 203-222 doi: 10.11144/ Javeriana.SC18-2.egcp.

Funding: Colciencias.

Electronic supplementary material: N/A

SICI: 2027-1352(201305/08)18:2<203:EEGDCPPLDMDLM>2.0.TS;2-P

\section{Introducción}

Desde hace tres décadas se ha reportado que los alimentos RTE (Ready To Eat) son el vehículo más frecuente en la transmisión de $L$. monocytogenes (Schlech et al. 1982, Rococurt 1996). En Estados Unidos existen informes de brotes de listeriosis humana (enfermedad de transmisión alimentaria, ETA, causada por este microorganismo) en varios estados relacionados con el consumo de salchicha, quesos y jamones (CDC 1999, CDC 2003). En países como Portugal se ha encontrado que cerca del $15 \%$ de los alimentos listos para el consumo están contaminados con L. monocytogenes (Guerra et al. 2001, Mena et al. 2004). En Colombia, pese a existir pocos datos, se ha encontrado que la frecuencia de este microorganismo en derivados cárnicos listos para el consumo fue de $24 \%$ (Vera 
et al. 2006). En el 2008 se encontró una frecuencia de L. monocytogenes en leche cruda de $9,6 \%$ y en quesos (incluyendo la cuajada) del 5,5\% (Gallegos et al. 2008); más recientemente la prevalencia encontrada en chorizo, jamón y salchicha fue de $4.0 \%, 6.13 \%$ y $7.69 \%$ respectivamente (GamboaMarín et al 2012).

Esta revisión presenta los miembros de género listeria cuya particularidad es que no todos son patógenos humanos o animales, se describen las características que hacen que $L$. monocytogenes sea un microorganismo con un impacto económico indeseable en la industria de alimentos y constituya un riesgo en salud pública. Por otra parte valorando que cepas del mismo serotipo pueden tener diferentes orígenes y virulencia diferente, se presenta la técnica de caracterización molecular PFGE variante CHEF la cual utiliza enzimas de restricción específicas que cortan con baja frecuencia el ADN de L. monocytogenes como la más adecuada para agrupar los serotipos en linajes evidenciando variaciones intraserotípicas. Finalmente se muestra en detalle el protocolo estandarizado de PulseNet, por el cual se están guiando muchos países del mundo para la caracterización molecular de L. monocytogenes.

L. monocytogenes (L. monocytogenes, patógeno humano y animal) pertenece al género Listeria el cual incluye otras 9 especies, L. ivanovii (patógeno animal), y las no patógenas, L. innocua, L. seeligeri, L. welshimeri, L. grayi, L. rocourtiae, L. fleischmannii, L. weibentephanensis y L. marthii (Pirie 1940, Leclercq et al. 2009, Graves et al. 2010, den Bakker et al. 2013, Lang-Halter et al. 2013). Este género está distribuido en el medio ambiente incluyendo el suelo, el agua, los drenajes, la vegetación, las heces de animales silvestres, ensilaje, en granjas y en instalaciones de procesamiento de alimentos.

L. monocytogenes, es un microorganismo indeseable en la industria de alimentos, por ser un contaminante potente (Assanta et al. 1990). Es un microorganismo Gram-positivo, móvil, no esporulado y aneróbico facultativo, puede sobrevivir con baja actividad de agua $\left(a_{w}\right)$, a altas concentraciones de sal y multiplicarse en temperaturas de -1 a $45^{\circ} \mathrm{C}$ y a $\mathrm{pH}$ entre 4,3 y 9,6 \pm 0.2 (Todd \& Notermans 2011). Adicionalmente tiene la habilidad de producir biofilms para adherirse a diferentes superficies, como el vidrio, el caucho y el acero inoxidable (Kalmokoff et al. 2001, Hassan et al. 2004), de tal manera que logra pasar todas la barreras diseñadas contra los patógenos en alimentos (Lou et al. 1999, Gardan et al. 2003). Por otra parte este microorganismo también presenta resistencia intrínseca a varios antimicrobianos; lo que hace más complejo el tratamiento de los pacientes con listeriosis (Ruiz-Bolivar et al. 2008, Ruiz-Bolivar et al. 2011b).

Impacto de la listeriosis en salud pública: La infección causada por $L$. monocytogenes se conoce con el nombre de listeriosis y se puede manifestar de dos formas, invasiva y no invasiva. La listeriosis invasiva se presenta principalmente en personas de edades extremas (recién nacidos y ancianos), mujeres embarazadas, personas con enfermedades que producen inmunosupresión y personas que reciben terapia inmunosupresora; generando en ésta población, meningitis, abortos, y septicemia entre otros, con una tasa de mortalidad del 20 al 30\% de los casos (Rocourt 1996, Torres et al. 2004, Torres et al. 2005). La listeriosis no invasiva, por el contrario se ha observado en algunos brotes de origen alimentario, donde la mayoría de los casos presentan síntomas de gastroenteritis, como diarrea, fiebre, cefalea y mialgia, tras un período de incubación corto. La listeriosis no invasiva puede afectar a toda la población y por lo general la enfermedad se soluciona de manera espontánea (Dalton et al. 1997, Torres et al. 2004, Torres et al. 2005).

La incidencia de listeriosis por ingesta de alimentos contaminados en el 2007 en Estados Unidos destacó que el grupo etéreo con más aislamientos fueron los adultos mayores de 65 años, seguido de niños menores de 5 años. En total se reportaron 1557 casos confirmados con más del $20 \%$ de mortalidad. En Estados Unidos entre el 2003 y el 2007, se presentó aumento en los casos de listeriosis, a diferencia de los reportes en Francia entre 1999 y 2005 en donde los casos pasaron de ser de 4,5 a 3,5 por cada millón de personas, pero en el 2006, se incrementó a 4,7 casos por cada millón de habitantes; el grupo etéreo más afectado 
fue al igual que en EU la población mayor de 65 años (Todd \& Notermans 2011).

En Colombia existen pocos datos sobre la epidemiología de la listeriosis, debido a que el microorganismo causante de la enfermedad no es de notificación obligatoria y al presentarse casos esporádicos no se asocia con enfermedad transmitida por alimentos (ETA; Vanegas et al. 2009, Ruiz-Bolivar et al. 2011b). Sin embargo, los datos del tercer período epidemiológico del 2008 revelaron 847 casos de ETA, donde la mayor incidencia se halló en Bogotá, Antioquia, Magdalena, Cundinamarca y Boyacá, el grupo etéreo más afectado fue de 15 a 44 años con más de 400 afectados (Grupo funcional ETA-SVCSPINS 2008). Por otra parte no existen estadísticas oficiales, sólo hay unos pocos reportes: en 1992 por el Hospital Central de la Policía de Bogotá (2 casos de listeriosis meníngea aguda supurativa y romboencefálica; Sánchez et al. 1992); en 1994 por el Hospital Universitario del Valle (3 casos de listeriosis neonatal; Payán \& Astudillo 1994); en 1999 por la Fundación Clínica Valle del Lili (19 casos: 10 en adultos inmunosuprimidos, 2 en mujeres embarazadas, 6 en neonatos y un adolescente; Crespo et al. 1999), en el 2001 por el Hospital Central de la Policía de Bogotá (1 caso de listeriosis perinatal; Sánchez et al. 2001), en el 2008 por la Universidad Libre de Cali (1 caso de listeriosis perinatal; Castillo-Cabezas \& Paredes 2008), en el 2009 por el Hospital Pablo Tobón Uribe (1 caso de listeriosis pediátrica; Chávez et al. 2009); por lo que aún no se puede dimensionar claramente el problema.

Impacto económico de la ETA por $L$. monocytogenes: Las ETA tienen un gran impacto económico; por ejemplo en los tratados de libre comercio se incrementa el flujo de alimentos entre países; lo cual significa que la comercialización de un producto alimenticio contaminado puede ocasionar ETA en diferentes puntos del planeta al mismo tiempo (Posfay-Barbe \& Wald 2009). Lo anterior genera además del impacto en salud pública, grandes pérdidas económicas ocasionadas por la presencia de brotes producidos por productos listos para el consumo, por ejemplo, en Canadá en el 2008, una compañía de alimentos perdió 43 millones de dólares al tener la obligación de recoger el producto contaminado de todos los expendios, mercados callejeros y grandes superficies donde habían sido distribuidos, y tuvo que invertir cerca de 27 millones en los procesos legales que tuvieron que enfrentar (Todd \& Notermans 2011).

Caracterización molecular de los aislamientos de L. monocytogenes: Los brotes de L. monocytogenes al parecer no son causados por las mismas cepas o serotipos; razón por la cual la caracterización molecular de los aislamientos es la manera de diferenciarlos o agruparlos (Lepe et al. 2012). En este sentido, es necesario utilizar métodos que permitan discriminar y subtipificar aislamientos de L. monocytogenes de diferentes orígenes (Kérouanton et al. 2010); lo que facilita tanto en salud pública como en la industria los estudios epidemiológicos, el análisis de la persistencia de algunas cepas, el análisis de riesgo así como el seguimiento y correlación de las cepas de los aislamiento (fuente del aislamiento-paciente).

El subdiagnóstico de la enfermedad en humanos, animales o la falta de datos de prevalencia en alimentos que existe en Colombia ha despertado interés en el uso de técnicas moleculares rápidas, sensibles y específicas como PCR (Polymerase Chain Reaction), qPCR (Real Time Polymerase Chain Reaction), REA (Restriction Ensyme Analysis), RAPD (Random Amplification of Polymorphic DNA) o ERIC-PCR (Enterobacterial Repetitive Intergenic Consensus Polymerase Chain Reaction), entre otras para la identificación, serotipificación, caracterización bioquímica, molecular y caracterización de la susceptibilidad antimicrobiana de los aislamientos nacionales de L. monocytogenes (Cai \& Kabuki 2002, Aguado et al. 2004, Vanegas et al. 2009, Ruiz-Bolivar et al. 2011a, Ruiz-Bolivar et al. 2011b, Gamboa-Marín et al. 2013).

En otros países, la tipificación de L. monocytogenes por PFGE (Pulsed Field Gel Electrophoresis), se ha convertido rápidamente en un método útil para la subtipificación de aislamientos de diferentes orígenes (alimentos, ambientes, brotes animales y humanos, entre otros; Destro et al. 1996, Hunter 
\& Gaston 1988, Autio et al. 1999, Johansson et al. 1999, Aarnisalo et al. 2003, Kérouanton et al. 2010), debido a que la técnica permite el uso de enzimas de restricción que cortan con baja frecuencia el DNA genómico de L. monocytogenes y por tanto producen perfiles simples (10 a 20 bandas), lo que facilita el análisis y la comparación de los resultados (Graves \& Swaminathan 2001).

De manera general la PFGE es una técnica que permite la separación de fragmentos de DNA de alto peso molecular (10 Kb a $10 \mathrm{Mb}$; Nassonova 2008) y tiene varias utilidades en el rastreo e investigación de los brotes de origen alimentario, también como la detección temprana de estos por el aumento de la incidencia de alguno de los subtipos usualmente implicados en brotes (Swaminathan 2001).

Origen de la Electroforesis en Gel de Campo Pulsado: En 1984 Schwartz y Cantor idearon una manera de separar moléculas grandes de DNA (hasta $10 \mathrm{Mb}$ ); hasta la fecha ha tenido una gran aceptación, así como una gama amplia de aplicaciones (Schwartz \& Cantor 1984, Nassonova 2008). En este método, el DNA viaja a través de un gel de agarosa concentrado, bajo la influencia de dos campos eléctricos. Los dos ángulos de los campos eléctricos se encuentran cerca a la perpendicularidad, no son uniformes en la intensidad de campo y cambian de manera alterna (pulsos). En general se supone que en concentraciones altas de agarosa y con tensiones elevadas, las moléculas grandes de DNA deben ser elongadas a lo largo de la dirección del campo eléctrico con el fin de penetrar a través de los poros del gel. Cuanto más grande sea la molécula de DNA, mayor será el tiempo para encontrar la nueva orientación y la retención en el gel (Southern et al. 1987).

Tipos y variantes de la Electroforesis en Gel de Campo Pulsado: El término original Electroforesis en Gel de Campo Pulsado (PFGE) fue utilizado por Schwartz y Cantor (1984) para cualquier separación en gel que emplease campos eléctricos múltiples y alternos. Existen otras variantes de la PFGE como: OFAGE (Orthogonal Field Alternating Gel Electrophoresis; Carle \& Olson 1984), FIGE (Field Inversion Gel Electrophoresis; Carle et al., 1986,
Birren \& Lai 1993), TAFE (Transverse AlternatingField Electrophoresis; Gardiner et al. 1986, Nassonova 2008), CHEF (Contour-Clamped Homogeneous Electric Field; Chu et al. 1986, Graves \& Swaminathan 2001), PACE (Programmable Autonomously Controlled Electrodes; Birren \& Lai 1993), RGE (Rotating Gel Electrophoresis; Southern et al. 1987), CFGE (Continuous Field Gel Electrophoresis; Birren \& Lai 1993), ZIFE (Zero-Integrated Field Electrophoresis; Birren \& Lai 1993) y ST/RIDE (Simultaneous Tangential/RectangularInversionDecussateElectrophoresis; Birren \& Lai 1993), las cuales implican variaciones en las características y posibilidades de los equipos (la disposición geométrica de los electrodos, homogeneidad, método para la reorientación de los campos eléctricos e intensidad del campo) y en cuanto a los resultados que se pueden obtener (velocidad de migración del DNA, resolución de bandas de DNA y la relación geométrica de los carriles de la muestras; Birren \& Lai 1993).

Electroforesis en Gel de Campo Pulsado (Pulse Field Gel Electrophoresis): En el dispositivo diseñado por Schwartz y Cantor, el campo eléctrico cambia en intervalos determinados formando ángulo de $90^{\circ}$ (Schwartz \& Cantor 1984). En un gel de forma rectangular un campo es homogéneo y es generado por dos filas de electrodos de puntos ubicados paralelamente y en lados opuestos del gel; el otro campo no es homogéneo y es generado por una fila de electrodos de puntos como cátodo y un electrodo de punto al lado opuesto como ánodo. Este sistema se conoce como "Electroforesis en Gradiente de Campo Pulsado" (PFGE). En este sistema, el ángulo entre los vectores de fuerza del campo varían en regiones diferentes del gel $\left(110^{\circ}\right.$ $150^{\circ}$ ), por lo tanto, las moléculas de igual tamaño migran con velocidades diferentes, dependiendo de su posición inicial en el gel; esto complica la comparación de las movilidades electroforéticas de los DNA que se encuentran en los carriles vecinos por lo que es imposible calcular con precisión la talla molecular. Otros experimentos han demostrado que un campo no homogéneo no es un requisito obligatorio para la separación exitosa del DNA. Debido a que la mayoría de sistemas actuales se basan en campos homogéneos, la abreviatura de "PFGE" tuvo entonces una nueva interpretación (Electroforesis en Gel de Campo 
Pulsado; Nassonova 2008).

Electroforesis de Campo Eléctrico Homogéneo Restringido al Contorno (Contour-clamped Homogeneous Electric Field): En esta PFGE el campo eléctrico es generado por varios electrodos organizados a lo largo de un contorno hexagonal, el campo es pulsado alternamente, generando así un ángulo de reorientación del $\mathrm{ADN}$ de aproximadamente $120^{\circ}$ (Figura 1). Esta técnica presenta varias ventajas en comparación a las mencionadas anteriormente,

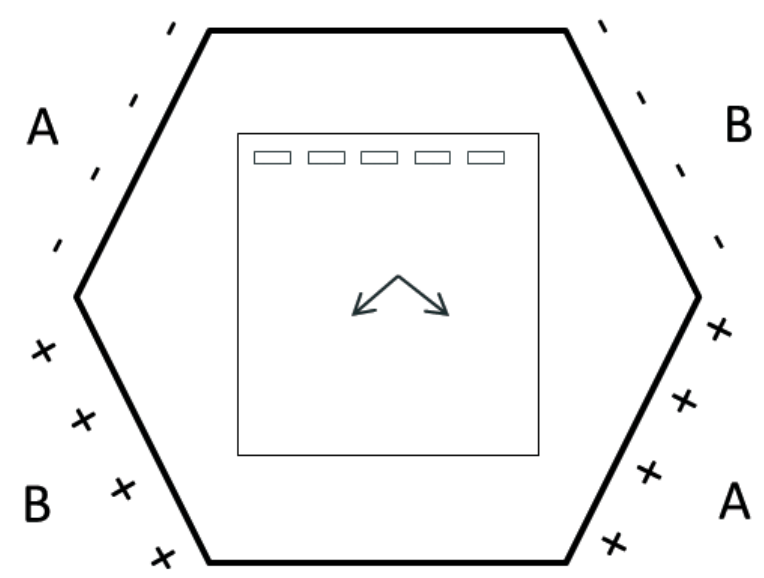

Fig. 1. Distribución de los electrodos en el equipo CHEF utilizado en PFGE. Flechas cortas muestran los vectores de fuerza de campo de los campos eléctricos alternantes. Símbolos $\mathrm{A}+\mathrm{y}$ $\mathrm{A}-, \mathrm{B}+$ y B- indican posiciones de los pares de electrodos de los campos eléctricos alternantes.

como son: mayor poder de separación (separa moléculas inferiores a $50 \mathrm{~Kb}$ sin distorsión y hasta moléculas de $2 \mathrm{Mb}$ ), los carriles electroforéticos son perfectamente rectilíneos y el patrón de separación es independiente de la posición del gel (Chu et al. 1986). Es por esto, que la variante CHEF de la PFGE es la utilizada en el protocolo estandarizado para tipificar molecularmente $L$. monocytogenes (Graves \& Swaminathan 2001).

En un estudio multicéntrico promovido por la Organización Mundial de la Salud (Brosch et al. 1996), se realizó la tipificación por medio de PFGE de 80 cepas de L. monocytogenes con el fin de estandarizar los métodos más apropiados en la técnica. Dentro de estos se incluyó el tipo de PFGE y se evaluaron las variantes CHEF y FIGE; sin embargo, en los cuatro laboratorios participantes se obtuvo resultados coherentes y correlacionados entre las dos variantes de PFGE utilizadas (CHEF y FIGE). Aunque en estas dos variantes los geles pueden resultar similares ya que las moléculas de DNA siguen carriles rectos, existen dos diferencias fundamentales por las cuales la CHEF se prefiere sobre la FIGE y las otras variantes de la PFGE: primero, la CHEF tiene mayor poder de resolución con moléculas de hasta $7 \mathrm{Mb}$ (el genoma de L. monocytogenes es de 2,9 $\mathrm{Mb}$ ) a diferencia de la FIGE que presenta un poder alto de resolución con moléculas entre 1 y $50 \mathrm{~Kb}$; segundo, el aparato diseñado para PFGE variante $\mathrm{CHEF}$ tiene la ventaja de poder separar mayor número de muestras ( 20) de $\mathrm{ADN}$ en cada corrida (Birren \& Lai 1993).

Usos generales de la Electroforesis en Gel de Campo Pulsado en epidemiología bacteriana: La PFGE ha demostrado ser una técnica altamente discriminatoria y por esto es utilizada en estudios epidemiológicos de brotes causados por microorganismos como Escherichia coli (Ejrnaes et al. 2006), Salmonella spp. (Olsen et al. 1994), Shigella spp. (Angelini et al. 2009), Listeria spp. (Nascentes et al. 2012), Campylobacter spp. (Behringer et al. 2011), y Vibrio cholerae, (Taneja et al. 2012) entre otros. La técnica se ha empleado para reconocer brotes de infección, detectar transmisión cruzada de patógenos nosocomiales, identificar la fuente de infección, reconocer las cepas particularmente virulentas y para el seguimiento de los programas de vacunación entre otros (Olive \& Bean 1999). Mediante el análisis de los patrones de PFGE, ya sea de manera visual (Tenover et al. 1995) o utilizando un software, se han podido determinar las similitudes genéticas entre los aislamientos, lo que permite inferir si dos aislamientos aparentemente no relacionados tienen la misma procedencia evolutiva (Tenover et al. 1995, Nascentes et al. 2012).

Electroforesis en Gel de Campo Pulsado (PFGE) en el estudio de la epidemiología molecular de L. monocytogenes: La PFGE de L. monocytogenes ha sido comparada en varios estudios con otros métodos de tipificación fenotípica y 
molecular (Giovannacci et al. 1999, Gravesen et al. 2000, Autio et al. 2003, Levin 2003, Chung-Hsi et al. 2006); en la mayoría de los casos ha resultado ser la técnica más discriminativa y reproducible. En estos estudios, se ha empleado el SID (Simpson's diversity index ó Diversity index; Hunter \& Gaston 1988) el cual se basa en la probabilidad que dos cepas no relacionadas sean ubicadas en diferentes grupos de tipificación. Este índice es utilizado para comparar métodos de tipificación con el fin de seleccionar el más discriminativo.

Boerlin et al. (1997), en su estudio demostraron que la PFGE era el método más discriminativo, seguido de REA, MEE (Multilocus Ensyme Electrophoresis) y por último la serotipificación; Giovannacci et al. (1999), hallaron que la técnica RAPD mostraba un poder discriminatorio mucho menor al de la PFGE; Aarnisalo et al. (2003), encontraron que la PFGE tenía mayor poder de discriminación que la ribotipificación; Autio et al. (2003), utilizaron PFGE, AFLP (Amplified Fragment Length Polymorphism) y la combinación de las dos técnicas, encontrando que incluso la PFGE por sí sola tenía mayor índice de discriminación que la combinación de las dos técnicas; Borucki et al. (2004), encontraron que el poder discriminatorio de la PFGE era mayor que el de la técnica MLST (Multilocus Sequence Typing) y este a la vez era superior al de la ribotipificación; Lukinmaa et al. (2004), encontraron que la discriminación de la PFGE era mayor a la de la ribotipificación y la serotipificación; Fugett et al. (2007), encontraron que la PFGE presentaba un mayor SID que la ribotipificación; Mammina et al. (2009), hallaron que la PFGE es más discriminatoria que la ribotipificación y esta a la vez que la PCR-RFLP (Polymerase Chain Reaction- Restriction Fragments Length Polymorphism); y finalmente, Ward et al. (2010), encontraron que la PFGE tenía mayor poder de discriminación que la MLGT (Multilocus Genotyping), concluyendo que este método es altamente discriminativo. Sin embargo, pese a conocerse que métodos como el MLVA (Multiple-Locus Variable Number of Tandem Repeat Analysis) y el MLST presentan mayor poder de discriminación que la PFGE (Revazishvili et al. 2004, Miya et al. 2008), sigue siendo la PFGE en su variante CHEF el método más utilizado para la diferenciación molecular de L. monocytogenes.
El poder discriminatorio de la PFGE-CHEF también ha sido determinado al utilizar diferentes enzimas de restricción. Para L. monocytogenes se han utilizado las siguientes endonucleasas de restricción ApaI, AscI, SmaI, NotI y Sse8387I; dentro de estas, Howard et al. (1992), encontraron que NotI genera grandes fragmentos lo que hace difícil la determinación de la talla molecular. Nakama et al. (1998), encontraron que Sse8387I presentaba menor poder de discriminación que $A p a \mathrm{I}, A s c \mathrm{I}$ y SmaI. Los resultados en cuanto a discriminación entre las enzimas $A p a \mathrm{I}, A s c \mathrm{I}$ y $S m a \mathrm{I}$ han variado considerablemente, dependiendo del origen de los aislamientos y su diversidad genética; sin embargo, se ha determinado que el uso de dos o más enzimas por lo general aumenta el poder discriminativo de la PFGE (Levin 2003), y la combinación de las enzimas $A p a \mathrm{I}$ y $A s c \mathrm{I}$ ha sido reportada por diversos autores como la combinación que presenta los mejores resultados para L. monocytogenes (Graves \& Swaminathan 2001).

Se muestran las enzimas (Tabla 1) que se han utilizado con mayor frecuencia para la digestión del DNA de L. monocytogenes, de las cuales la mayoría, excepto, $X b a \mathrm{I}$ tienen secuencias de reconocimiento ricas en GC. El genoma de L. monocytones tiene un tamaño de $2,9 \mathrm{Mb}$ y un contenido bajo de G-C (37,8 \%; Torres et al. 2005), es por esto que se utilizan enzimas de restricción con secuencias de cortes ricas en estos nucleótidos y que la digestión con dichas enzimas generan patrones de PFGE con pocas bandas (de 10 a 20); lo que facilita el análisis.

Tabla 1. Enzimas endonucleasas de restricción utilizadas y recomendadas para la caracterización molecular de L. monocytogenes por PFGE.

\begin{tabular}{lccc}
\hline Enzima & $\begin{array}{c}\text { Secuencia palindrómica } \\
\left(5^{\prime} \rightarrow 3^{\prime}\right)\end{array}$ & $\%$ AT & $\%$ GC \\
\hline ApaI & GGGCC $^{\wedge} \mathrm{C}$ & 0 & 100 \\
AscI & $\mathrm{GG}^{\wedge} \mathrm{CGCGCC}$ & 0 & 100 \\
NotI & $\mathrm{GC}^{\wedge}$ GGCCGC & 0 & 100 \\
SmaI & $\mathrm{CCC}^{\wedge}$ GGG & 0 & 100 \\
Sse8387I & $\mathrm{CCTGCA}^{\wedge} \mathrm{GG}$ & 25 & 75 \\
XbaI & $\mathrm{T}^{\wedge} \mathrm{CTAGA}^{\circ}$ & 50 & 50 \\
\hline
\end{tabular}


Anteriormente el protocolo para la PFGE tomaba alrededor de 7 días, por lo que muchos investigadores preferían emplear técnicas más rápidas aunque su poder discriminativo fuese menor; además, existían muchas discrepancias en cuanto a los tiempos de la corrida electroforética, temperatura de corrido, concentración y $\mathrm{pH}$ de las soluciones, calidad de los reactivos, enzimas de restricción y voltajes empleados en el procedimiento.

En el2001 Graves y Swaminathan estandarizaron el protocolo para la subtipificación de L. monocytogenes por PFGE, realizando ajustes que incluían el uso de células bacterianas obtenidas directamente de cultivo en placa, tratamiento de pre-lisis con lisozima, 2 h de lisis, reducción del tiempo de los lavados utilizando agua precalentada y tampón TE (0,01 M Tris-EDTA, pH $8 \pm 0,2)$, usando tiempos mínimos de digestión con las enzimas de restricción, y utilizando agarosa SeaKem Gold (Lonza, Alphareta GA, USA) para electroforesis, con lo que lograron la reducción del tiempo a $30 \mathrm{~h}$ a partir de la obtención del cultivo puro (Graves \& Swaminathan 2001), lo que significa una reducción sustancial en el tiempo del proceso $(83 \%)$ y en el costo de la prueba.

A partir de esta estandarización, los resultados de las investigaciones fueron fácilmente comparables, y se generó una base de datos internacional. PulseNet es una red nacional de laboratorios de salud pública y agencia de reglamentación de alimentos, coordinado por los Centros para el Control y Prevención de Enfermedades (CDC; www.cdc. gov/pulsenet). PulseNet fue creado en Atlanta, USA en 1995 y la red en América Latina y el Caribe en el 2004, promoviendo la utilización de PFGE para el seguimiento epidemiológico y tipificación de patógenos con el fin de fortalecer la vigilancia y el sistema de respuesta en cada uno de los países y regiones en los que se está implementando. Los patrones son sometidos vía electrónica a una base de datos dinámica en el CDC, disponible bajo demanda a los participantes, la cual permite rápidamente la comparación de los patrones.

Protocolo estandarizado por PulseNet: La bacteria se cultiva en placas de agar BHI a $37^{\circ} \mathrm{C}$ por 16-18 h. Las células se transfieren de las placas de petri a tubos plásticos de $15 \mathrm{ml}$ que contengan $3 \mathrm{ml}$ de tampón TE 1X, usando un hisopo estéril, se ajusta la densidad celular con turbidímetro a un rango entre 0,79 y 0,81 . Se transfiere la suspensión celular $(\sim 240 \mu \mathrm{l})$ a tubos de microcentrífuga de $1,5 \mathrm{ml}$ y se añaden $60 \mu \mathrm{l}$ de solución de lisozima $10 \mathrm{mg} / \mathrm{ml}$ (Sigma, St. Louis, MO) mezclando con pipeta. La mezcla se incuba en baño termostatado a $37^{\circ} \mathrm{C}$ por $10 \mathrm{~min}$. Pasado este tiempo se añade igual volumen de una solución de 1,2\% (p/v) de agarosa SeaKem Gold, 1\% (p/v) de dodecilsulfato de sodio (SDS), 0,2 $\mathrm{mg} / \mathrm{ml}$ de proteinasa $\mathrm{K}$ (Roche Molecular Biochemicals, Indianapolis, IN) preparada en agua destilada estéril, mantenida a temperatura entre $53-56^{\circ} \mathrm{C}$, luego se homogeniza suavemente con la pipeta repetidas veces. La mezcla $(600 \mu \mathrm{l})$ se divide en dos moldes reutilizables (300 $\mu$ cada uno), (Bio-Rad, Hercules, CA) y se deja enfriar por 5 min. Los bloques de agarosa se transfieren a tubos plásticos de polipropileno de $50 \mathrm{ml}$ que contengan $4 \mathrm{ml}$ de tampón de lisis (50

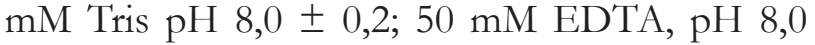
$\pm 0,2 ; 1 \%(\mathrm{p} / \mathrm{v})$ lauril sarcosinato de sodio, 0,15 $\mathrm{mg} / \mathrm{ml}$ Proteinasa $\mathrm{K}$ ), se incuba por $2 \mathrm{~h}$ entre 50 y $54^{\circ} \mathrm{C}$ en baño termostatazo con agitación orbital a $200 \mathrm{rpm}$. Luego de la proteólisis se decanta la solución de lisis y se lavan los bloques dos veces con $15 \mathrm{ml}$ de agua destilada estéril precalentada $\left(50-54^{\circ} \mathrm{C}\right)$ por $10 \mathrm{~min}$ cada uno, seguidos de cuatro lavados con tampón TE 1X (cada lavado durante 15 min) a la temperatura y condiciones de agitación previamente descritas. Terminado el proceso los bloques se cortan entre 2 y $2,5 \mathrm{~mm}$, utilizando el accesorio para corte de gel. Los bloques se pueden almacenar hasta el momento de la digestión en 1,5 $\mathrm{ml}$ de tampón TE $1 \mathrm{X}$ a $4^{\circ} \mathrm{C}$.

Para la digestión del DNA de alto peso molecular (intacto y contenido en los bloques de agarosa) se emplean las enzimas $A s c \mathrm{I}$ (New England BioLabs, Beverly, MA) o ApaI (Roche Molecular Biochemicals) en soluciones tampón de acuerdo a las instrucciones del fabricante de las enzimas. La restricción con $A s c$ I se realiza a una concentración de $25 \mathrm{U}$ por bloque durante $3 \mathrm{~h}$ a $37{ }^{\circ} \mathrm{C}$ o con $A p a \mathrm{I}$ a una concentración de 160 $200 \mathrm{U}$ por bloque durante $5 \mathrm{~h}$ a $30^{\circ} \mathrm{C}$. Una vez completado el proceso de digestión los bloques se 
separan por electroforesis en gel de agarosa 1\% (p/v) SeaKem Gold en solución tampón 0,5 X de Tris-borato-EDTA (TBE) a $14^{\circ} \mathrm{C}$ en un aparato PFGE CHEF-Mapper (BioRad). La electroforesis se lleva a cabo con tiempos de pulso de 4 a 40 $\mathrm{s}$, por $22 \mathrm{~h}$, con ángulo de $120^{\circ}$, gradiente de 6 $\mathrm{V} / \mathrm{cm}$, a $14^{\circ} \mathrm{C}$. Posteriormente, los geles se tiñen durante 15 a $20 \mathrm{~min}$ en $250 \mathrm{ml}$ de agua desionizada conteniendo $25 \mu \mathrm{l}$ de bromuro de etidio $(10 \mathrm{mg} /$ $\mathrm{ml}$ ) y se destiñen con tres lavados de 20-30 min cada uno usando $500 \mathrm{ml}$ de agua desionizada. El análisis de los patrones se realiza con el software Molecular Analyst Fingerprinting Plus (BioRad; Graves \& Swaminathan 2001).

Es importante destacar que la última actualización del Procedimiento Operativo Estándar para la PFGE de L. monocytogenes realizado por PulseNet (versión 2013; http://www.cdc. gov/pulsenet/PDF/listeria-pfge-protocol-508c. pdf; PulseNet 2013), considera el uso de la enzima de restricción $X b a \mathrm{I}$ para la codigestión con $A s c \mathrm{I}$ y que posteriormente el material resultante debe ser digerido nuevamente con ApaI. En esta actualización, también, se recomienda el uso de albúmina de suero bovino (BSA) durante la restricción enzimática, con el fin de reducir al mínimo la incidencia de las restricciones parciales.

Interpretación de los perfiles PFGE: Diversos estudios han analizado los patrones resultantes de la electroforesis de manera visual (Bille \& Rocourt 1996, Dalton et al. 1997, Nakama et al. 1998, Aarnisalo et al. 2003, Gudmundsdóttir et al. 2005, Chiu et al. 2006, Orndorff et al. 2006, Lindstedt et al. 2008, Sauders et al. 2009, Kérouanton et al. 2010, Latorre et al. 2010), basándose en el criterio de tipificación de cepas bacterianas propuesto por Tenover et al., (1995); en el cual si dos patrones no difieren en sus bandas, se consideran indistinguibles y por lo tanto las cepas analizadas pueden asociarse en un brote; si dos patrones difieren de 2 a 3 bandas, se consideran estrechamente relacionados y las cepas posiblemente hacen parte del brote; si dos patrones difieren de 4 a 6 bandas, se consideran posiblemente relacionados y las cepas pueden hacer parte del brote; y si dos patrones difieren en 7 o más bandas, se consideran diferentes y por lo tanto no hacen parte del brote. Sin embargo, el análisis visual se presta para la obtención de resultados subjetivos, lo que se evidencia en la falta de concordancia entre los estudios (Birren \& Lai 1993).

Tenover efectivamente demostró que la interpretación de las diferencias en el número de bandas entre un par de aislamientos permite agruparlos o no; sin embargo, este tipo de análisis estaría soportado por un número mínimo de eventos mutacionales (por ejemplo, dos aislamientos que difieren en dos-tres bandas serían consideradas como estrechamente relacionados desde un único suceso genético) pero esto no siempre ocurre así. Recientemente, desde el CDC propusieron que los criterios de Tenover no eran de aplicación general para la investigación de brotes de origen alimentario, debido a que los fenómenos de transferencia genética, superposición de bandas y otros artefactos podrían afectar la relación de los perfiles y la interpretación (Comunicación personal El Dr. José Antonio Lepe, de la Unidad Clínica de Enfermedades Infecciosas, Microbiología y Medicina Preventiva. Hospital Universitario Virgen del Rocio, Sevilla, España). De acuerdo con los nuevos criterios adoptados para L. monocytogenes una banda de diferencia puede ser considerada significativa para distinguir entre dos perfiles (Barrett et al. 2006). De otro lado la interpretación del patrón de bandeo de la PFGE requiere muchas decisiones subjetivas y que dicha subjetividad aumenta la variabilidad de los perfiles y en consecuencia, afecta la forma en que se interpretan los resultados en la lectura visual (Gerner-Smidt et al. 1998).

Por otra parte PulseNet hace varios años desarrolló un protocolo para el análisis computarizado de perfiles de PFGE, utilizando el software BioNumerics para desplazar la lectura visual y pese a que el protocolo ha evolucionado hacia la interpretación automatizada, algunas de sus medidas obliganalusuarioa tomardecisionescríticas durante el análisis, en particular para la asignación de bandas anormales y para la interpretación de perfiles estrechamente relacionados; siendo lo anterior una desventaja importante de la PFGE a la hora de la normalización del protocolo (GernerSmidt et al. 2006). 
No obstante el uso de software para el análisis de los patrones, genera resultados más reproducibles, confiables y comparables. Estos programas por lo general, se basan en el índice de coincidencia de Dice (1945) el cual se calcula mediante la siguiente ecuación:

$$
S n_{x y}=\frac{2 n_{x y}}{n_{x}+n_{y}}
$$

Donde: $S_{x y}$ es la similitud entre las cepas $x$ y $y$, $n_{x y}$ es el número de bandas en común en los dos perfiles de DNA, y $n_{x} \mathrm{y} n_{y}$ son los números de bandas exhibidas por las cepas $x$ y $y$ respectivamente.

También es posible determinar la similitud mediante el índice de Jaccard (1901), como se utilizó en el estudio de Zunabovic (Zunabovic et al. 2011), el cual se calcula mediante la siguiente ecuación:

$$
I J=\frac{C}{A+B-C}
$$

Donde: $A$ es el número de atributos presentes en la OTU (Unidad Taxonómica Operacional) $A$, $B$ es el número de atributos presentes en la OTU B, y $\mathrm{C}$ es el número de atributos comunes presentes en las OTUs $A$ y $B$ (Real et al. 1997).

Por último, también es utiliza para determinar la similitud entre cepas el coeficiente de Simpson el cual se calcula de la manera siguiente:

$$
\text { Coef. Simpson }=\frac{C}{N}
$$

Donde: $C$ es el número de bandas compartidas entre las dos cepas y $N$ es el número de bandas del patrón de restricción con el mayor número de bandas entre cada uno de los pares emparejados (Proctor et al. 1995).

Estos índices que se utilizan para determinar la similaridad tienen características comunes: se pueden expresar fácilmente, la interpretación es fácil y directa, el rango de expresión (matriz de similitud) oscila entre 0 y 1 y permiten posibilidades como considerar la presencia de elementos exclusivos, la no ponderación especial de ninguna categoría y la ponderación especial de alguna categoría (Saiz 1980, Foerster et al. 2013, Travouillon et al. 2013). En los estudios consultados para esta revisión, el $67 \%$ utilizó el índice de coincidencia de Dice (1945), y 31,6 \% el índice de Jaccard (1901); el coeficiente de Simpson (Proctor et al. 1995), lo ha utilizado tan sólo el $1,4 \%$, por lo que se evidencia el primer método como el más común para hallar la similitud entre los patrones de las cepas estudiadas.

Para generar el dendrograma, se utiliza el método computacional UPGMA (Jain et al. 2000, Foerster et al. 2013); el cual es un algoritmo de agrupación jerárquica que consiste en la búsqueda de la distancia más pequeña en la matriz de distancias genéticas y el agrupamiento de las unidades que la conforman como una sola unidad taxonómica independiente. Así, se calculan los promedios de la nueva unidad contra las restantes generando una nueva matriz y se repite el proceso hasta que todas las unidades quedan unidas a un único elemento (ancestro hipotético; Jain et al. 2000). De esta manera se logra la elaboración de un diagrama en forma de árbol basado en la similitud de los aislamientos, llamado dendrograma. El punto de corte (cutoff) empleado para determinar la similitud entre los clusters es $80 \%$ (Luizaga de Monteiro et al. 2013, Rivoal et al. 2013).

A partir de la agrupación de los patrones mediante dendrogramas, basados en PFGE $\mathrm{u}$ otras técnicas moleculares, ha sido posible la clasificación por distancias genéticas de los aislamientos de L. monocytogenes en 3 grupos o linajes genéticos. El linaje I que corresponde a los serotipos $1 / 2 \mathrm{~b}, 3 \mathrm{~b}, 4 \mathrm{~b}, 4 \mathrm{~d}, 4 \mathrm{e}$ y 7 ; el linaje II que corresponde a los serotipos $1 / 2 \mathrm{a}, 3 \mathrm{a}, 1 / 2 \mathrm{c}$ y $3 \mathrm{c}$; y el linaje III que incluye los serotipos 4a y 4c así como algunas cepas de serotipo 4b (Dice 1945, Bille \& Rocourt 1996, Olive \& Bean 1999, Dauphin et al. 2001, Graves \& Swaminathan 2001, Nadon et al. 2001, Autio et al. 2002, Crum 2002, Larsen et al. 2002, Lukinmaa et al. 2004, Kérouanton 
et al. 2010, Di Ciccio et al. 2012, Ferronatto et al. 2012). En años recientes, se ha reportado la existencia de un cuarto linaje (IV) el cual fue identificado por primera vez mediante la técnica MLGT y se compone de aislamientos obtenidos principalmente de rumiantes, de los serotipos 4a, $4 \mathrm{~b}$ y 4c; los que difieren considerablemente de los aislamientos que pertenecen al linaje III, (Orsi et al. 2011). Ninguno de los artículos revisados en los que se caracterizan cepas $L$. monocytogenes por PFGE (Tabla 2) menciona el linaje IV, lo que sugiere que las enzimas empleadas actualmente para la PFGE, aún no permiten discriminar entre los miembros de los linajes III y IV.
Para lograr la agrupación de los linajes es necesario la serotipificación y la realización del dendrograma. No obstante, el origen de los aislamientos unido al serotipo pueden dar una idea anticipada sobre el linaje al que podrían corresponder los aislamientos, ya que por lo general se concibe que los linajes I y II son los que albergan los serotipos más comúnmente asociados con brotes alimentarios, incluidos los serotipos $1 / 2$ a (linaje II) y los serotipos $1 / 2 \mathrm{~b}$ y $4 \mathrm{~b}$ (linaje I), las cepas del linaje II son comunes en alimentos, vegetación, granjas y aislamientos de casos de listeriosis animal, así como de casos esporádicos en humanos (Torres et al. 2004, Belalcazar et al. 2005, Orsi et al. 2011).

Tabla 2. Linajes y serotipos de L. monocytogenes que han sido identificados en varios estudios.

\begin{tabular}{|c|c|c|c|}
\hline $\begin{array}{l}\text { Linaje I } \\
(1 / 2 b, 3 b, 4 b, 4 d, 4 e \text { y } 7)\end{array}$ & $\begin{array}{l}\text { Linaje II } \\
(1 / 2 a, 3 a, 1 / 2 c \text { y } 3 c)\end{array}$ & $\begin{array}{l}\text { Linaje III } \\
(4 a \text { y } 4 c \text { algunos } 4 b)\end{array}$ & Referencias \\
\hline $\begin{array}{l}\text { División IIA: } 1 / 2 b, 3 b \\
\text { División IIB: } 4 \mathrm{~b}, 4 \mathrm{~d}, 4 \mathrm{e}\end{array}$ & División I & No reportado & (Brosch 1994) \\
\hline Linaje I: $1 / 2 b, 3 b, 4 b, 4 d$ & Linaje II & Linaje III & (Neves et al. 1998) \\
\hline Grupo Genómico II: $1 / 2 b, 4 b, 4 c, 7$ & Grupo Genómico I: $1 / 2 a, 1 / 2 c, 3 a$ & Grupo Genómico III: 4 a & (Keto-Timonen et al. 2003) \\
\hline Grupo I: $1 / 2 b, 4 b$ & Grupo II: $1 / 2 a, 1 / 2 c$ & No reportado & (Gudmundsdottir et al. 2004) \\
\hline Grupo I: $1 / 2 b, 4 b$ & Grupo II: $1 / 2 a, 1 / 2 c$ & No reportado & (Harvey et al. 2004) \\
\hline Linaje I: $1 / 2 b, 3 b, 4 b$ & Linaje II: $1 / 2 a, 1 / 2 c, 3 a$ & No reportado & (Evans Gilbreth et al. 2005) \\
\hline División II: $1 / 2 \mathrm{~b}, 3 \mathrm{~b}, 4 \mathrm{~b}, 4 \mathrm{~d}, 4 \mathrm{e}$ & División I & No reportado & (Chiu et al. 2006) \\
\hline Grupo II: $1 / 2 b, 3 b, 4 b, 4 c, 4 d$ & Grupo I: 1/2a, 3a & No reportado & (Chou \& Wang 2006) \\
\hline Linaje I: $1 / 2 b, 3 b, 4 b, 4 d, 4 e$ & Linaje II: $1 / 2 a, 3 a$ & No reportado & (Shen et al. 2006) \\
\hline Linaje II: $1 / 2 b, 3 b, 4 b$ & Linaje I: $1 / 2 a, 1 / 2 c$ & No reportado & (Bērzin ${ }_{s}$ š et al. 2007) \\
\hline Linaje I: $1 / 2 b, 3 b, 4 b$ & Linaje II: $1 / 2 a, 1 / 2 c, 3 a$ & Linaje III & (Fugett et al. 2007) \\
\hline Linaje II: $1 / 2 b, 3 b, 4 b, 4 d, 4 e$ & Linaje I & No reportado & (Hellstrom et al. 2008) \\
\hline Linaje I: $1 / 2 b, 4 b$ & Linaje II: $1 / 2 a, 1 / 2 c$ & Linaje III & (Miya et al. 2008) \\
\hline Linaje $I: 1 / 2 b, 4 b$ & Linaje II: $1 / 2 a$ & No reportado & $\begin{array}{l}\text { (Keto-Timonen et al. 2003, } \\
\text { Khelef et al. 2006) }\end{array}$ \\
\hline Linaje I: $1 / 2 b, 3 b, 7$ & Linaje II & Linaje III: $4 \mathrm{a}, \mathbf{4 c}$ & (Sauders et al. 2009) \\
\hline Linaje I: $1 / 2 b, 4 b$ & Linaje II: $1 / 2 a, 1 / 2 c$ & Linaje III: $4 a, 4 c$ & (Nucera et al. 2010) \\
\hline Linaje I: $1 / 2 b, 3 b, 4 b, 4 d, 4 e$ & Linaje II & Linaje III & (O'Connor et al. 2010) \\
\hline Linaje $I: 1 / 2 b, 4 b$ & Linaje II: $1 / 2 \mathrm{a}, 1 / 2 \mathrm{c}$ & Linaje III & (Ward et al. 2010) \\
\hline Linaje I: no especificado & Linaje II: no especificado & Linaje III: no especificado & (Williams et al. 2011) \\
\hline Linaje I: $1 / 2 b, 4 b, 7$ & Linaje II: $1 / 2 a$ & Linaje III: no especificado & (Pagadala et al. 2012) \\
\hline
\end{tabular}


Las cepas de los linajes III y IV por otra parte son raras y han sido aisladas fundamentalmente de fuentes animales, principalmente de rumiantes y otros mamíferos no primates por lo que la información que se tiene de estas es escasa, ocasionalmente se ha aislado de casos clínicos humanos (Orsi et al. 2011, Tsai et al. 2011).

Caracterización de L. monocytogenes por PFGE en algunos países de América: En América, Estados Unidos y Canadá son los países que han reportado con mayor frecuencia brotes asociados a L. monocytogenes (Torres et al. 2004, Warriner \& Namvar 2009, Cartwright et al. 2013); lo cual se debe a sus sistemas de vigilancia, el "Foodborne Disease Outbreak Surveillance System del Centers for Disease Control and Prevention (CDC)" y el "Canadian Network for Public Health Intelligence (CNPHI)" del "Public Health Alerts Center (PHAC)" respectivamente, los cuales incluyen la caracterización por medio de PFGE, que alimenta el sistema PulseNet.

En estudio de revisión (Cartwright et al. 2013) de los brotes de listeriosis en Estados Unidos entre 1998 y 2008, se evaluó la inclusión de L. monocytogenes en "PulseNet"; encontrando que existía un aumento de 9 veces en el número de reportes de brotes de listeriosis, el cual fue atribuido a una mayor detección a través del programa (PulseNet). Por otra parte, los brotes en el segundo período del estudio fueron generalmente más cortos en el tiempo y con un menor número de casos. Estos resultados sugieren que las medidas de control aplicadas en la industria y la vigilancia por el programa PulseNet fueron efectivas. En los países latinoamericanos aún es escasa la información en cuanto a la epidemiología y brotes de listeriosis, debido a que la enfermedad no se diagnostica con frecuencia. Sin embargo, en los últimos años se ha empleado la PFGE para el estudio de la presencia y persistencia (Vongkamjan et al. 2013) de cepas de L. monocytogenes en las industrias de procesamiento de alimentos, logrando la detección de las fuentes de contaminación y de la presencia de las cepas persistentes para la elaboración de un plan de limpieza y desinfección más efectivo (Brito et al. 2008, Cruz et al. 2008, Sequeira Mendonça 2009, von Laer et al. 2009, Nascentes Galvão et al. 2012).
En Brasil (Lemes-Marques et al. 2007) se utilizó la PFGE y la serotipificación para la realización del dendrograma que clasificó los aislamientos de L. monocytogenes en tres grupos; desafortunadamente, las fuentes de exposición al microorganismo no se pudieron determinar para los 12 casos clínicos evaluados y como no existían datos epidemiológicos previos, no se pudo determinar una relación concluyente entre los aislamientos. En Chile, (Cordano \& Jacquet 2009), utilizando la PFGE se determinó la presencia de L. monocytogenes en ensaladas de verduras frescas y congeladas, preparadas y comercializadas en supermercados en Santiago de Chile (Foerster et al. 2012) y los patrones de PFGE encontrados permitieron detectar la relación entre aislamientos provenientes de carne de ave comprada en tiendas locales y aislamientos de pacientes con listeriosis.

En un estudio realizado en Argentina (Laciar \& Centorbi 2002), la PFGE permitió diferenciar entre cepas de un mismo serotipo y cepas que parecían ser similares. La PFGE fue más discriminatoria que la serotipifiación y permitió la caracterización de todas las cepas, incluso las que no pudieron ser fagotipificadas. Este estudio demostró la presencia de L. monocytogenes en muestras de alimentos de origen marino provenientes de la costa Atlántica de Argentina.

En México, se determinó la prevalencia, tipos y distribución geográfica de las cepas de $L$. monocytogenes aisladas de quesos frescos (MorenoEnriquez et al. 2007). En esta investigación se encontró que a partir de una misma muestra se podrían encontrar diferentes pulsotipos, lo que puede indicar diferentes fuentes de contaminación y un mayor riesgo para los consumidores. En Colombia hasta la fecha, aún no se han publicado estudios en los cuales se utilice la PFGE como herramienta para la tipificación molecular de $L$. monocytogenes; sin embargo, sí se ha utilizado esta técnica desde hace más de una década en estudios epidemiológicos con otros microorganismos como Pseudomonas aeruginosa (Garzón 2000), Shigella flexneri (Hidalgo et al. 2002), Klebsiella pneumoniae (Espinal et al. 2004, Mantilla et al. 2006), Streptococcus pneumoniae (Moreno et al. 2004), Salmonella Typhimurium (Muñoz et al. 2006), Salmonella Typhi 
(Cardona-Castro et al. 2007), Acinetobacter baumannii (Yomayusa et al. 2008), y Escherichia coli (Gaitán C et al. 2009). La implementación de la técnica PFGE en el país es necesaria para generar datos epidemiológicos, de prevalencia y persistencia de las cepas de $L$. monocytogenes en las industrias de procesamiento de alimentos con el fin de conocer las fuentes de diseminación y establecer medidas de control de tal manera que se reduzca el riesgo de adquirir listeriosis por el consumo de alimentos contaminados. Por otra parte, el proyecto que soporta esta revisión se ha propuesto dentro sus objetivos la caracterización molecular por PFGE (variante CHEF) de los aislamientos de $L$. monocytogenes que resulten del estudio, siguiendo la indicaciones técnicas de PulseNet, de tal manera que los resultados obtenidos sean comparables y sean de utilidad para el gobierno y la industria.

\section{Conclusión}

La Electroforesis en Gel de Campo Pulsado (PFGE) es la técnica molecular Gold Standard para la tipificación y diferenciación de los aislamientos de $L$. monocytogenes, al tratarse de una técnica con alto poder discriminatorio, con resultados reproducibles, de rápida ejecución y comparación. La PFGE permite el agrupamiento de los aislamientos en tres linajes de serotipos, aunque posiblemente no se pueda discriminar entre en linaje III y el IV reportado por otros autores. La variante CHEF (Contour-clamped Homogeneous Electric Field) es la única utilizada para la tipificación de L. monocytogenes. La combinación de las enzimas de restricción $A s c \mathrm{I}$ y $A p a \mathrm{I}$ son las más frecuentemente utilizadas ya que generan mayor poder de discriminación en la técnica; sin embargo, en la actualización 2013 del protocolo PulseNet se recomienda la co-digestión XbaI-AscI, seguida de la digestión con $A p a \mathrm{I}$. El protocolo de PFGE más adecuado para la tipificación molecular de L. monocytogenes es el estandarizado por Graves y Swaminathan (2001) para PulseNet. No obstante, se deben estandarizar las condiciones en cada laboratorio. En Colombia (a saber) aún no se han publicado trabajos de caracterización molecular de L. monocytogenes por PFGE, lo cual contrasta con el hecho de que la notificación de este microorganismos en alimentos aún no es obligatoria y también con el subdiagnóstico existente de este patógeno. Por otra parte en Latinoamérica el uso de la técnica debe ser promovido para generar bases de datos a fin de fortalecer la vigilancia en cada uno de los países y para conocer los clones existentes, sus fuentes de origen y generar medidas de control fundamentadas en la evidencia propia.

Finalmente es claro que técnicas moleculares como MLVA y MLST han mostrado mayor capacidad para detectar variaciones intraserotipicas y para la discriminación entre aislamientos de L. monocytogenes; sin embargo, la mayoría de los investigadores utilizan la PFGE estandarizada por PulseNet para que sus resultados puedan ser comparados a nivel mundial y aportar al conocimiento epidemiológico de la listeriosis.

\section{Agradecimientos}

Este trabajo pertenece al proyecto "Diseño de un plan integral para reducir la prevalencia de Salmonella spp., y Listeria monocytogenes en plantas de beneficio, desposte y puntos de venta en la cadena cárnica porcina" Financiado por Colciencias y ejecutado en alianza con Asoporcicultores-FNP-CENIPORCINO (Proyecto. No. 120358635758). Registrado en la Vicerrectoría de Investigaciones de la Pontificia Universidad Javeriana (Código No. 0005386).

\section{Conflicto de intereses}

Los autores no tienen conflictos de intereses en relación a este trabajo ni con ninguna de las marcas existentes que puedan proveer reactivos con especificaciones similares. Así mismo, las marcas comerciales referidas al interior del texto se presentan sólo con la intensión de mostrar exactamente como está estandarizado el protocolo de PulseNet.

\section{Referencias}

Aarnisalo K, Autio T, Sjöberg A-M, Lundén J, Korkeala $\mathrm{H}$, et al. (2003) Typing of Listeria monocytogenes isolates originating from the food processing industry with automated ribotyping and PulsedField Gel Electrophoresis. Journal of Food Protection 66: 249-255 
Aguado V, Vitas AI, García I (2004) Characterization of Listeria monocytogenes and Listeria innocua from a vegetable processing plant by RAPD and REA. International Journal of Food Microbiology 90: 341-347 doi: 10.1016/S0168-1605(03)00313-1

Angelini M, Guedes Stehling E, Moretti ML, Dias da Silveira W (2009) Molecular epidemiology of Shigella spp strains isolated in two different metropolitam areas of southeast Brazil. Brazilian Journal of Microbiology 40: 685-692

Assanta A, Roy D, Goulet J, Savoie L, Roy R (1990) Efficiency of sanitizing agents for destroying Listeria monocytogenes on contaminated surfaces. Diary Science 73: 3428 - 3432 doi: 10.3168/jds. S0022-0302(90)79040-6

Autio T, Hielm S, Miettinen M, Sjoberg A-M, Aarnisalo K, et al. (1999) Sources of Listeria monocytogenes contamination in a cold-smoked rainbow trout processing plant detected by PulsedField Gel Electrophoresis typing. Applied and Environmental Microbiology 65: 150-155 code 0099$2240 / 99 / \$ 04.0010$

Autio T, Keto-Timonen R, Lundén J, Björkroth J, Korkeala H (2003) Characterisation of persistent and sporadic Listeria monocytogenes strains by PulsedField Gel Electrophoresis (PFGE) and Amplified Fragment Length Polymorphism (AFLP). Systematic Applyed Microbiology 26: 539-545 code: 07232020/03/26/04-539\$15.00/0

Autio T, Lundén J, Fredriksson-Ahomaa M, Bjorkroth J, Sjoberg A-M, et al. (2002) Similar Listeria monocytogenes pulsotypes detected in several foods originating from different sources. International Journal of Food Microbiology 77: 83-90 code: S01681605(02)00055-7

Barrett TJ, Gerner-Smidt P, Swaminathan B (2006) Interpretation of Pulsed-Field Gel Electrophoresis patterns in foodborne disease investigations and surveillance. Foodborne Pathogens and Disease 3: 20-31 doi:10.1089/fpd.2006.3.20

Belalcazar ME, Poutou RA, Torres KJ, Gallegos JM, Torres O, et al. (2005) Listeria monocytogenes y listeriosis animal. Revista UDCA Actualidad y Divulgación Cientifica 8: 3-16

Bērzins š A, Hörman A, Lundén J, Korkeala H (2007) Factors associated with Listeria monocytogenes contamination of cold-smoked pork products produced in Latvia and Lithuania. International Journal of Food Microbiology 115: 173-179 doi:10.1016/j.ijfoo dmicro.2006.10.021

Behringer M, Miller WG, Oyarzabal OA (2011) Typing of Campylobacter jejuni and Campylobacter coli isolated from live broilers and retail broiler meat by flaA-
RFLP, MLST, PFGE and REP-PCR. Journal of Microbiological Methods 84: 194-201 doi: 10.1016/ j.mimet.2010.11.016

Bille J, Rocourt J (1996) WHO internacional multicenter Listeria monocytogenes subtyping studyrationale and setup of the study. International Journal of Food Microbiology 32: 251-262 code: S0168-160-1605(96)01140-3:

BioRad (2000) Microfiltration Apparatus Instruction Manual. Catalog 170-6545, ed., BIORAD, 16p

Birren B, Lai E (1993) Pulsed Field Gel Electrophoresis: A practical guide., ed., Academic Press Inc., San Diego, California, USA.

Boerlin P, Bannerman E, Bille J, Jemmi T (1997) Typing Listeria monocytogenes isolates from fish products and human listeriosis cases. Applied and Environmental Microbiology 63: 1338-1343 code: 0099$2240 / 97 / \$ 04.00+0$

Borucki MK, Hyun Kim S, Call DR, Smole SC, Pagotto F (2004) Selective discrimination of Listeria monocytogenes epidemic strains by a mixed-genome DNA microarray compared to discrimination by Pulsed-Field Gel Electrophoresis, ribotyping, and multilocus sequence typing. Journal of Clinical Microbiology 42: 5270-5276 doi:10.1128/ JCM.42.11.5270-5276.2004

Brito JRF, Santos EMP, Arcuri EF, Lange CC, Brito MAVP, et al. (2008) Retail Survey of Brazilian Milk and Minas Frescal Cheese and a Contaminated Dairy Plant To Establish Prevalence, Relatedness, and Sources of Listeria monocytogenes Isolates. Applied and Environmental Microbiology 74: 4954-4961 doi: 10.1128/AEM.01828-07

Brosch R, Brett M, Catimel B, Luchansky JB, Ojeniyi B, et al. (1996) Genomic fingerprinting of 80 strains from the WHO multicenter international typing study of Listeria monocytogenes via Pulsed-Field Gel Electrophoresis (PFGE). International Journal of Food Microbiology 32: 343-355

Brosch R, Chen, J., Luchansky, J.B. (1994) PulsedField fingerprinting of Listeriae: Identification of genomic divisions for Listeria monocytogenes and their correlation with serovar. Applied and Environmental Microbiology 60: 2584-2592 code: 00992240/94/\$04.00+0

Cai S, Kabuki DY (2002) Rational design of DNA sequence- based strategies for subtyping Listeria monocytogenes. Journal of Clinical Microbiology 40: 33193325 doi: 10.1128/JCM.40.9.3319-3325.2002

Cardona-Castro NM, Sánchez-Jiménez MM, Usuga-Silva LY, Arboleda-Naranjo M, Garzón E, et al. (2007) Caracterización de dos brotes de fiebre tifoidea en Apartadó, Antioquia, 2005. Biomédica 27: 236-243 
Carle GF, Frank M, Olson MV (1986) Electrophoretic separations of large DNA molecules by periodic inversion of the electric field. Science 232: 65-68 doi: $10.1126 /$ science. 3952500

Carle GF, Olson MV (1984) Separation of chromosomal DNA molecules from yeast by orthogonal-fieldalternation gel electrophoresis. Nucleic Acid Research 12: $5647-5664$

Cartwright EJ, Jackson KA, Johnson SD, Graves LM, Silk BJ, et al. (2013) Listeriosis outbreaks and associated food vehicles, United States, 1998-2008. Emerging Infectious Diseases 19: 1-10

Castillo-Cabezas E, Paredes R (2008) Listeriosis y embarazo. Una enfermedad poco diagnosticada. Revista Colombiana Salud Libre 3: 207-213.

CDC (1999) Update: Multistate Outbreak of Listeriosis in United States, 1998-1999, Morbidity Mortality Weekly Reports 1117-1118

CDC (2003) Preliminary FoodNet Data on the Incidence of Foodborne Illnesses Selected Sites, United States 2002, Morbidity and Mortality Weekly Report 52: 340-343

ChávezJ, Calume M, Guerrero J, Urrego A, Almanza Ret al. (2009) Caso de meningitis bacteriana relacionado con el consumo de queso fresco contaminado con Listeria monocytogenes. Informe Quincenal Epidemiológico Nacional 14: 305-320.

Chung-Hsi C, Chinling W (2006) Genetic relatedness between Listeria monocytogenes isolates from seafood and humans using PFGE and REP-PCR. International Journal of Food Microbiology 110: 135-148 doi: 10.1016/j.ijfoodmicro.2006.02.003

Cordano AM, Jacquet C (2009) Listeria monocytogenes isolated from vegetable salads sold at supermarkets in Santiago, Chile: Prevalence and strain characterization. International Journal of Food Microbiology 132: 176-179 doi: 10.1016/j.ijfoodmicro.2009.04.008

Crum NF (2002) Update on Listeria monocytogenes Infection. Current Gastroenterology Reports 4: 287-296 doi: 10.1007/s11894-002-0078-z

Cruz CD, Silvestre FA, Kinoshita EM, Landgraf M, Franco BDGM, et al. (2008) Epidemiological survey of Listeria monocytoegenes in a GRAVLAX salmon processing line. Brazilian Journal of Microbiology 39: 375-383

Chiu S, Vanderlinde PB, Dykes GA (2006) A comparison of selected methods for measuring the virulence properties of Listeria spp. Canadian Journal of Microbiology 52: 301-307 doi: 10.1139/W05-129

Chou C-H, Wang C (2006) Genetic relatedness between Listeria monocytogenes isolates from seafood and humans using PFGE and REP-PCR. International Journal of Food Microbiology 10: 135-148 doi:10.1016/ j.ijfoodmicro.2006.02.003
Chu G, Vollrath D, Davis RW (1986) Separation of large DNA molecules by contour-clamped homogeneous electric fields. Science 234: 1582-1585 doi: $10.1126 /$ science. 3538420

Crespo MP, Vélez JD, Castañeda C, Hoyos F, López ML et al. (1999) Aislamiento de Listeria monocytogenes en un hospital de tercer nivel. Colombia Médica 30: 89-98.

Dalton CB, Austin C, Sobel J, Hayes P, Bibb W, et al. (1997) An outbreak of gastroenteritis and fever due to Listeria monocytogenes in milk. The New England Journal of Medicine 336: 100-105

Dauphin G, Ragimbeau C, Malle P (2001) Use of PFGE typing for tracing contamination with Listeria monocytogenes in three cold-smoked salmon processing plants. International Journal of Food Microbiology 64: 51 61 code: S0168-1605(00)00442-6

Den Bakker HC, Manuel CS, Fortes ED, Wiedmann M, Nightingale KK (2013) Genome sequencing identifies Listeria fleischmannii subsp. coloradensis subsp. nov., a novel Listeria fleischmannii subspecies isolated from a ranch in Colorado. International Journal of Systematic and Evolutionary Microbiology IN PRESS: doi: 10.1099/ijs.0.048587-0

Destro MT, Leitao MFF, Farber JM (1996) Use of molecular typing methods to trace the dissemination of Listeria monocytogenes in a shrimp processing plant. Applied and Environmental Microbiology 62: 705-711 code: 0099-2240/96/\$04.00+0

Di Ciccio P, Meloni D, Festino AR, Conter M, Zanardi E, et al. (2012) Longitudinal study on the sources of Listeria monocytogenes contamination in coldsmoked salmon and its processing environment in Italy. International Journal of Food Microbiology 158: 7984 doi:10.1016/j.ijfoodmicro.2012.06.016

Dice LR (1945) Measures of the amount of ecologic association between species. Ecology 26: 297-302

Ejrnaes K, Sandvang D, Lundgren B, Ferry S, Holm S et al. (2006) Pulsed-Field Gel Electrophoresis typing of Escherichia coli strains from samples collected before and after pivmecillinam or placebo treatment of uncomplicated communityacquired urinary tract infection in women. Journal of Clinical Microbiology 44: 1776-1781 doi: 10.1128/ JCM.44.5.1776-1781.2006

Espinal PA, Mantilla JR, Saavedra CH, Leal AL, Alpuche C, et al. (2004) Epidemiología molecular de infección nosocomial por Klebsiella pneumoniae productora de beta-lactamasas de espectro extendido. Biomédica 24: 252-261

Evans Gilbreth S, Call JE, Wallace FM, Scott VN, Chen Y, et al. (2005) Relatedness of Listeria monocytogenes isolates recovered from selected ready-to-eat foods and listeriosis patients in the United States. Applied and Environmental Microbiology 71: 8115-8122 doi:10.1128/AEM.71.12.8115-8122.2005 
Ferronatto AI, Payão Pellegrini DdC, Guerra P, de Itapema Cardoso MR (2012) Distribuição de grupos clonais de Listeria monocytogenes em carcaças e no ambiente de matadouros frigoríficos de suínos. Archives of Veterinary Science 17: 42-49

Foerster C, Gonzalez-Hein G, Troncoso M, Figueroa G (2012) Pulsed-field gel electrophoresis pattern similarities between Listeria monocytogenes isolated from human patients and poultry in Chile. CyTA - Journal of Food 10.1080/19476337.2012.673176

Fugett EB, Schoonmaker-Bopp D, Dumas NB, Corby J, Wiedmann M (2007) Pulsed-Field GelElectrophoresis (PFGE) analysis of temporally matched Listeria monocytogenes isolates from human clinical cases, foods, ruminant farms, and urban and natural environments reveals source-associated as well as widely distributed PFGE types. Journal of Clinical Microbiology 45: 865873 doi:10.1128/JCM.01285-06

Gaitán SL, Espinal PA, Grupo de Investigación en Resistencia Bacteriana Región Caribe (2009) Caracterización molecular de Escherichia coli $y$ Klebsiella pneumoniae productores de $\beta$-lactamasas de espectro extendido en hospitales de la Región Caribe, Colombia. Revista Chilena de Infectología 26: 239-246

Gallegos JM, Vanegas MC, Albarracín Y, Máttar S, Poutou RA, et al. (2008) Frequency of isolation of Listeria spp., in different retail foods in Colombia. Animal Production Research Advances 4: 9-18

Gamboa-Marín A, Buitrago SM, Pérez-Pérez KI, Mercado M, Poutou-Piñales RA, et al. (2012) Prevalence of Listeria monocytogenes in pork-meat and other processed products from the Colombian swine industry. Revista MVZ Córdoba 17: 2827-2833

Gamboa-Marín A, Mejía-Wagner DC, Moreno-Ocampo PA, Buitrago SM, Pérez-Pérez KI, et al. (2013) Antimicrobial susceptibility of Listeria moncytogenes, Listeria ivanovii, and Listeria species isolated from swine processing facilities in Colombia Journal of Swine Health and Production 21: 10-21

Gardan R, Cossart PELGC, Labadie J (2003) Identification of Listeria monocytogenes genes involved in salt and alkaline $\mathrm{pH}$ tolerance. Applied and Environmental Microbiology 69: 3137-3143 doi: 10.1128/ AEM.69.6.3137-3143.2003

Gardiner K, Laas W, Patterson D (1986) Fractionation of large mammalian DNA restriction fragments using vertical Pulsed-Field Gradient Gel Electrophoresis. Somatic Cell Molecular Genetic 12: 185-195

Garzón K (2000) Molecular de aislados nosocomiales de Pseudomonas aeruginosa en Santafé de Bogotá, D.C. Colombia. Tesis de Maestría. Depto. Microbiología. Pontificia Universidad Javeriana, Bogotá, D.C., Colombia
Gerner-Smidt P, Hise K, Kincaid J, Hunter S, Rolando S, et al. (2006) PulseNet USA: a five-year update. Foodborn Pathogens and Disease 3: 9-19

Gerner-Smidt P, Graves LM, Hunter S, Swaminathan B (1998) Computerized analysis of Restriction Fragment Length Polymorphism patterns: comparative evaluation of two commercial software packages. Journal of Clinical Microbiology 36: 1318-1323 code: 0095-1137/98/\$04.0010

Giovannacci I, Ragimbeau C, Queguiner S, Salvat G, Vendeuvre J-L, et al. (1999) Listeria monocytogenes in pork slaughtering and cutting plants use of RAPD, PFGE and PCR-REA for tracing and molecular epidemiology. International Journal of Food Microbiology 53: 127-140 PII: S0168-1605(99)00141-5

Graves LM, Helsel LO, Steigerwalt AG, Morey RE, Daneshvar MI, et al. (2010) Listeria marthii sp. nov., isolated from the natural environment, finger lakes national forest. International Journal of Systematic and Evolutionary Microbiology 60: 1280-1288 doi:10.1099/ ijs.0.014118-0

Graves LM, Swaminathan B (2001) PulseNetstandardized protocol for subtyping Listeria monocytogenes by macrorestriction and pulsed-field gel electrophoresis. International Journal of Food Microbiology 65: 55-62 PII: S0168-1605Ž00.00501-8

Gravesen A, Jacobsen T, Moller PL, Hansen F, Larsen AG, et al. (2000) Genotyphing of Listeria monocytogenes comparison of RAPD, ITS and PFGE. International Journal of Food Microbiology 57: 43-51 doi: 10.1016/ S0168-1605(00)00234-8

Grupo funcional ETA-SVCSP-INS. Informe de la vigilancia de las enfermedades transmitidas por alimentos, http:// www.invima.gov.co/Invima/general/docs_general/ INFORMEETA_\%20ITRIM ESTRE2008.pdf 2008.

Gudmundsdottir KB, Aalbæk B, Sigurdarson S, Gunnarsson E (2004) The diversity of Listeria monocytogenes strains from 10 Icelandic sheep farms. Journal of Applied Microbiology 96:913-921 doi:10.1111/ j.1365-2672.2004.02183.x

Guerra MM, McLauchlin J, Bernardo FA (2001) Listeria in Ready-to-eat and Unprocessed Foods Produced in Portugal. Food Microbiology 18: 423-429 doi: 10.1006/ fmic.2001.0421

Gudmundsdóttir S, Gudbjörnsdóttir B, Lauzona HL, Einarssonb H, Kristinssonc KG, et al. (2005) Tracing Listeria monocytogenes isolates from cold-smoked salmon and its processing environment in Iceland using pulsed-field gel electrophoresis. Internacional Journal of Food Microbiology 101: 41-51 doi:10.1016/ j.ijfoodmicro.2004.08.023

Harvey J, Norwood DE, Gilmour A (2004) Comparison of repetitive element sequence-based PCR with 
multilocus enzyme electrophoresis and pulsed field gel electrophoresis for typing Listeria monocytogenes food isolates. Food Microbiology 21: 305-312 doi:10.1016/ j.fm.2003.08.003

Hassan AN, Birt DM, Frank JF (2004) Behavior of Listeria monocytogenes in a Pseudomonas putida biofilm on a condensate forming surface. Journal of Food Protection 67: 322-327

Hellstrom S, Kiviniemi K, Autio T, Korkeala H (2008) Listeria monocytogenes is common in wild birds in Helsinki region and genotypes are frequently similar with those found along the food chain. Journal of Applied Microbiology 104: 883-888 doi:10.1111/j.13652672.2007.03604.x

Hidalgo M, Realpe ME, Muñoz N, Sicard D, Silva E, et al. (2002) Brote de enfermedad diarreica aguda causado por Shigella flexneri en una escuela de Madrid, Cundinamarca:caracterización fenotípica y genotípica de los aislamientos. Biomédica 22: 272-279

Howard PJ, Harsono KD, Luchansky JB (1992) Differentiation of Listeria monocytogenes, Listeria innocua, Listeria ivanovii, and Listeria seeligeri by PulsedField Gel Electrophoresis. Applied and Environmental Microbiology 58: 709-712 code 0099-2240/92/020709$04 \$ 02.00 / 0$

Hunter PR, Gaston MA (1988) Numerical index of the discriminatory ability of typing systems: an application of Simpson's index of diversity. Journal of Clinical Microbiology 26: 2465-2466 code 0095$1137 / 88 / 112465-02 \$ 02.00 / 0$

Jaccard P (1901) Étude comparative de la distribution floral dans une portion des Alpes et des Jura. Bulletin del la Société Vaudoise des Sciences Naturelles 37: 547555

Jain AK, Murty MN, Flynn PJ (2000) Data clustering: A review. ACM Computing Surveys 31: 264-323 ACM 0360-0300/99/0900-0001\$5.00

Johansson T, Rantala L, Palmu L, Honkanen-Buzalski T (1999) Ocurrence and Typing of Listeria monocytogenes Strains in Retail Vacuum-packed Fish Products and in a Production Plant. International Journal of Food Microbiology 47: 111-119

Kalmokoff ML, Austin JW, Wan XD, Sanders G, Banerjee S, et al. (2001) Adsorption, attachment and biofilm formation among isolates of Listeria monocytogenes using model conditions. Journal of Applied Microbiology 91: 725-734 doi: 10.1046/j.13652672.2001.01419.x

Kérouanton A, Marault M, Petit L, Grout J, Dao T'T, et al. (2010) Evaluation of a multiplex PCR assay as an alternative method for Listeria monocytogenes serotyping. Journal of Microbiological Methods 80: 134137 doi:10.1016/j.mimet.2009.11.008
Keto-Timonen RO, Autio TJ, Korkeala HJ (2003) An Improved amplified Fragment Length Polymorphism (AFIP) protocol for discrimination of Listeria isolates. Systematic Applied Microbiology 26: 236-244 code: 072.12020/03/26/02-2'16 \$15.00/0

Khelef N, Lecuit M, Buchrieser C, Cabanes D, Dussurget O, et al. (2006) Listeria monocytogenes and the genus Listeria, 3rd ed., Springer, New York, USA,

Laciar AL, Centorbi ONP (2002) Listeria species in seafood: isolation and characterization of Listeria spp. from seafood in San Luis, Argentina. Food Microbiology 19: 645-651

Lang-Halter E, Neuhaus K, Scherer S (2013) Listeria weihenstephanensis sp. nov., isolated from the water plant Lemna trisulca of a german fresh water pond. International Journal of Systematic and Evolutionary Microbiology 63(2):641-647 doi: 10.1099/ijs.0.036830-0

Larsen CN, Nørrung B, Sommer HM, Jakobsen M (2002) In vitro and In vivo invasiveness of different Pulsed-Field Gel Electrophoresis types of Listeria monocytogenes. Applied and Environmental Microbiology 68: 5698-5703 doi: 10.1128/AEM.68.11.56985703.2002

Latorre AA, van Kessel JS, Karns JS, Zurakowski MJ, Pradhan AK, etal. (2010) Biofilm in milking equipment on a dairy farm as a potential source of bulk tank milk contamination with Listeria monocytogenes. Journal of Dairy Science 93: 2792-2802 doi: 10.3168/jds.20092717

Leclercq A, Clermont D, Bizet C, Grimont PAD, Le Fleche-Mateos A, et al. (2009) Listeria rocourtiae sp. nov. International Journal of Systematic and Evolutionary Microbiology 60: 2210-2214 doi: 10.1099/ijs.0.017376-0

Lemes-Marques E, Durante Cruz C, Destro MT (2007) Pheno-andgenotypic characterization of Listeria monocytogenes clinical isolates from the southwestern region of the state of Sao Paulo, Brazil. Brazilian Journal of Microbiology 38: 287-292

Lepe JA, Torres MJ, Liró J, Luque R, Aznar J, et al. (2012) Caracterización microbiológica de los aislados de Listeria monocytogenes procedentes de casos humanos en Andalucía. Enfermedades Infecciosas y Microbiología Clínica 30: 602-607 doi: 10.1016/ j.eimc.2012.02.012

Levin RE (2003) Application of Random Amplified Polymorphic DNA (RAPD) and Pulsed-Field Gel Electrophoresis (PFGE) analysis to Listeria monocyfogenes: A review of metbodology and resuts. Food Biotechnology 17: 217-236 doi: IO.1081/FBT120026344

Lindstedt B-A, Tham W, Danielsson-Tham M-L, Vardund T, Helmersson S, et al. (2008) Multiplelocus variable-number tandem-repeats analysis of 
Listeria monocytogenes using multicolour capillary electrophoresis and comparison with pulsed-field gel electrophoresis typing. Journal of Microbiological Methods 72: 141-148 doi:10.1016/j.mimet.2007.11.012:

Lou Y, Yousef AE (1999) Characteristics of Listeria monocytogenes important to food processors, in Ryser ET, Marth, E.H., (Eds). Listeria, Listeriosis and Food Safety. Marcel Dekker Inc, 2nd, New York, p. 131224

Luizaga de Monteiro LR, de Mesquita AJ, Dantas MC, Borges André P, Lamaro Cardoso J (2013) Molecular characterization of Listeria monocytogenes isolated from animal products in a city of Northern Brazil. Ciencia Rural, Santa María 43: 1443-1448

Lukinmaa S, Aarnisalo K, Suihko M-L, Siitonen A (2004) Diversity of Listeria monocytogenes isolates of human and food origin studied by serotyping, automated ribotyping and pulsed-field gel electrophoresis. Clinical Microbiology and Infection 10: 562-568 doi: 10.1111/j.1469-0691.2004.00876.x:

Mammina C, Manfreda G, Aleo A, De Cesare A, Pellissier N, et al. (2009) Molecular typing reveals frequent clustering among human isolates of Listeria monocytogenes in Italy. Journal of Food Protection 72: 876880

Mantilla JR, Reguero MT, González EB, García IA, Leal AL, et al. (2006) Caracterización molecular de un brote por Klebsiella pneumoniae productora de CTX-M12 en la unidad de cuidado intensivo neonatal de un hospital colombiano. Biomédica 26: 408-414

Mena C, Almeida G, Carneiro L, Teixeira P, Hogga T, et al. (2004) Incidence of Listeria monocytogenes in different food products commercialized in Portugal. Food Microbiology 21: 213-216 doi: 10.1016/S07400020(03)00057-1

Miya S, Kimura B, Sato M, Takahashi H, Ishikawa T, et al. (2008) Development of a multilocus variablenumber of tandem repeat typing method for Listeria monocytogenes serotype $4 \mathrm{~b}$ strains. International Journal of Food Microbiology 124: 239-249 doi:10.1016/j.ijfoodm icro.2008.03.023:

Moreno-Enriquez RI, Garcia-Galaz A, Acedo-Felix E, Gonzalez-Rios H, Call JE, et al. (2007) Prevalence, types, and geographical distribution of Listeria monocytogenes from a survey of retail queso fresco and associated cheese processing plants and dairy farms in Sonora, Mexico. Journal of Food Protection 70: 25962601

Moreno J, Phandanouvong V, Castañeda E (2004) Vigilancia molecular de aislamientos invasores de Streptococcus pneumoniae resistentes a la penicilina en niños colombianos menores de 5 años. Biomédica 24: 296-301
Muñoz N, Realpe ME, Castañeda E, Agudelo CI (2006) Caracterización por Electroforesis de Campo Pulsado de aislamientos de Salmonella Typhimurium recuperados en el programa de vigilancia de enfermedad diarreica aguda en Colombia, 19972004. Biomédica 26: 397-407

Nadon CA, Woodward DL, Young C, Rodgers FG, Wiedmann M (2001) Correlations between molecular subtyping and serotyping of Listeria monocytogenes. Journal of Clinical Microbiology 39: 2704-2707 doi: 10.1128/JCM.39.7.2704-2707.2001:

Nakama A, Terao M, Kokubo Y, Itoh T, Maruyama T, et al. (1998) A comparison of Listeria monocytogenes serovar $4 \mathrm{~b}$ isolates of clinical and food origin in Japan by pulsed-field gel electrophoresis. International Journal of Food Microbiology 42: 201-206 PII: S01681605(98)00084-1:

Nascentes Galvão N, Chiarini E, Destro MT, de Aguiar Ferreira M, Nero LA (2012) PFGE characterisation and adhesion ability of Listeria monocytogenes isolates obtained from bovine carcasses and beef processing facilities. Meat Science 92: 635-643 doi:10.1016/ j.meatsci.2012.06.011:

Nassonova ES (2008) Pulsed Field Gel Electrophoresis: Theory, instruments and application. Cell and Tissue Biology 2: 557-565 doi: 10.1134/ S1990519X08060011:

Neves E, Lourenc o A, Silva AC, Coutinho R, Brito L (1998) Pulsed-field gel electrophoresis (PFGE) analysis of Listeria monocytogenes isolates from different sources and geographical origins and representative of thetwelve serovars. Systematic and Applied Microbiology 31: 387-392 doi:10.1016/j.syapm.2008.08.005:

Nucera D, Lomonaco S, Bianchi DM, Decastelli L, Grassi MA, et al. (2010) A five year surveillance report on PFGE types of Listeria monocytogenes isolated in Italy from food and food related environments. International Journal of Food Microbiology 140: 271-276 doi:10.1016/ j.ijfoodmicro.2010.04.016:

O'Connor L, O'Leary M, Leonard N, Godinho M, O'Reilly C, et al. (2010) The characterization of Listeria spp. isolated from food products and the foodprocessing environment. Letters in Applied Microbiology 51: 490-498 doi:10.1111/j.1472-765X.2010.02928.x:

Olive DM, Bean P (1999) Principles and applications of methods for DNA-Based Typing of microbial organisms. Journal of Clinical Microbiology 37: 16611669 code 0095-1137/99/\$04.00+0:

Olsen JE, Skov MN, Threlfall EJ, Brown DJ (1994) Clonal lines of Salmonella enterica serotype enteritidis documented by IS200-, ribo-, Pulsed-Field Gel Electrophoresis and RFLP typing. Journal of Medical Microbiology 40: 15-22 
Orndorff PE, Hamrick TS, Washington Smoak I, Havell EA (2006) Host and bacterial factors in listeriosis pathogenesis. Veterinary Microbiology 114: 1-15 doi:10.1016/j.vetmic.2005.12.003:

Orsi RH, den Bakker HC, Wiedmann M (2011) Listeria monocytogenes lineages: Genomics, evolution, ecology, and phenotypic characteristics. International Journal of Medical Microbiology 301: 79-96 doi:10.1016/ j.ijmm.2010.05.002:

Pagadala S, Parveen S, Rippen T, Luchansky JB, Call JE, et al. (2012) Prevalence, characterization and sources of Listeria monocytogenes in blue crab (Callinectus sapidus) meat and blue crab processing plants. Food Microbiology 31: 263-270 doi:10.1016/j.fm.2012.03.015:

Payán A, Astudillo M (1994) Listeriosis neonatal: ¿Enfermedad poco frecuente o no diagnosticada?. Enfoque microbiológico. Colombia Médica 25: 69-72.

Pirie JHH (1940) Listeria: Change of name for a genus of bacteria. Nature 145: 264

Posfay-Barbe KM, Wald ER (2009) Listeriosis. Seminars in Fetal \& Neonatal Medicine 14: 228-233.

Proctor ME, Brosch R, Mellen JW, Garrett LA, Kaspar CW, et al. (1995) Use of Pulsed-field Gel Electrophoresis to link sporadic cases of invasive listeriosis with recalled chocolate milk. Applied and Environmental Microbiology 61: 3177-3179 code 00992240/95/\$04.0010:

Real C, Alcalá MD, Muñoz-Páez A, Criado JM (1997) XAFS analysis of the potassium-silica interaction in rice husks. Nuclear Instruments and Methods in Physics Research B 133: 68-72 PII S0168-583X(97) 00462-X:

Revazishvili T, Kotetishvili M, Colin Stine O, Kreger AS, Glenn Morris J, et al. (2004) Comparative analysis of multilocus sequence typing and PulsedField Gel Electrophoresis for characterizing Listeria monocytogenes strains isolated from environmental and clinical sources. Journal of Clinical Microbiology 42: 276285 doi: 10.1128/JCM.42.1.276-285.2004:

Rivoal K, Fablet A, Courtillon C, Bougeard S, Chemaly M et al. (2013) Detection of Listeria spp. in liquid egg products and in the egg breaking plants environment and tracking of Listeria monocytogenes by PFGE. International Journal of Food Microbiology 166: 109-116 doi: 10.1016/j.ijfoodmicro.2013.06.014

Rocourt J (1996) Risk factors for listeriosis. Food Control 7: 195-202 PII S0956-7135(96)00035-7:

Ruiz-Bolivar Z, Carrascal-Camacho AK, NeuqueRico MC, Gutiérrez-Triviño C, Rodríguez-Bocanegra MX, et al. (2011a) Enterobacterial repetitive intergenic consensus-polymerase chain reaction (ERIC-PCR) fingerprinting reveals intra-serotype variations among circulating Listeria monocytogenes strains. African Journal of Microbiology Research 5: 1586-1598

Ruiz-Bolivar Z, Neuque-Rico MC, Poutou-Piñales RA, Carrascal-Camacho AK, Máttar-Velilla S (2011b) Antimicrobial susceptibility of $L$. monocytogenes foodisolates from different cities of Colombia. Fooborne Pathogens and Disease 8: 913-919 doi: 10.1089/ fpd.2010.0813:

Ruiz-Bolivar Z, Poutou-Piñales RA, CarrascalCamacho AK (2008) Resistencia antimicrobiana y a desinfectantes de Listeria spp. NOVA 6: 201-218

Saiz F (1980) Experiencias en el uso de criterios de similitud en el estudio de comunidades. Archivos de Biologia y Medicina Experimental 13: 387-402

Sánchez E, Castillo A, Ortega C (2001) Infección perinatal por Listeria. Reporte de un caso. Revista Colombiana de Obstetricia y Ginecología 52: 199-202

SánchezE, Pardo R, Duque A, Palomino S, Reyes E (1992). Listeriosis del Sistema Nervioso Central: Formas meníngea aguda supurativa y romboencefálica, Acta Neurologica Colombiana 8: 165-168

Sauders BD, Sanchez MD, Rice DH, Corby J, Stich S, et al. (2009) Prevalence and molecular diversity of Listeria monocytogenes in retail establishments. Journal of Food Protection 72: 2337-2349

Schlech WF, Lavigne PM, Bortolussi RA, Allen AC, Haldane EV, et al. (1982) Epidemic Listeriosis. Evidence for transmission by food. The New England Journal of Medicine 308: 203-206 doi: 10.1056/ NEJM198301273080407

Schmid MW, Ng EYW, Lampidis R, Emmerth M, Walcher M, et al. (2005) Evolutionary history of the genus Listeria and its virulence genes. Systematic and Applied Microbiology 28: 1-18

Schwartz DC, Cantor CR (1984) Separation of yeast chromosome-sized DNAs by Pulsed Field Gradient Gel Electrophoresis. Cell 37: 67-75

Sequeira Mendonça K (2009) Diversidade genética de cepas de Listeria monocytogenes isoladas na região sul do Rio Grande do Sul através de PFGE. Programa de pós-graduação em ciência e tecnologia agroindustrial. Universidade Federal de Pelotas, Pelotas, Brasil

Sequeira Mendonça K, Brenner Michael G, Eucares von Laer A, Blum Menezes D, Ribeiro Itapema Cardoso M, et al. (2012) Genetic relatedness among Listeria monocytogenes isolated in foods and food production chain in southern Rio Grande do Sul, Brazil. Food Control 28: 171-177

Shen Y, Liu Y, Zhang Y, Cripe J, Conway W, et al. (2006) Isolation and characterization of Listeria monocytogenes 
Isolates from ready-to-eat foods in Florida. Applied and Environmental Microbiology 72: 5073-5076 doi:10.1128/ AEM.00435-06:

Southern EM, Anand R, Brown WRA, Fletcher DS (1987) A model for the separation of large DNA molecules by crossed field gel electrophoresis. Nucleic Acids Research 15: 5925-5943

Swaminathan B (2001) Listeria monocytogenes, in Doyle MP, Beuchat, L.R., Montville, T.J., (Eds). Food Microbiology; Fundamentals and Frontiers. American Society for Microbiology, Washington, D.C., p. 383-409

Taneja N, Sangar G, Chowdhury G, Ramamurthy T, Mishra A, et al. (2012) Molecular epidemiology of Vibrio cholerae causing outbreaks and sporadic cholera in northern India. Indian Journal of Medical Research 136: 656-663

Tenover FC, Arbeit RD, Goering RV, Mickelsen PA, Murray BE, et al. (1995) Interpreting chromosomal DNA restriction patterns produced by Pulsed-Field Gel Electrophoresis: criteria for bacterial strain typing. Journal of Clinical Microbiology 33: 2233-2239 code 0095-1137/95/\$04.0010:

Todd ECD, Notermans S (2011) Surveillance of listeriosis and its causative pathogen, Listeria monocytogenes. Food Control 22: 1484-1490 doi:10.1016/ j.foodcont.2010.07.021:

Torres KJ, Sierra SC, Poutou RA, Carrascal AK, Mercado M (2005) Patogénesis de Listeria monocytogenes, microorganismo zoonótico emergente. Revista MVZCórdoba 10: 511-543

Torres KJ, Sierra SC, Poutou RA, Vera H, Carrascal AK, et al. (2004) Incidencia y diagnóstico de Listeria monocytogenes; microorganismo zoonótico emergente en la industria de alimentos. Revista UDCA Actualidad \& Divulgación Cientifica 7: 25-57

Travouillon KJ, Archer M, Legendre S, Hand SJ (2007) Finding the Minimum Sample Richness (MSR) for multivariate analyses: implications for palaeoecology. Historical Biology 19: 315-320 doi: 10.1080/08912960 701388576

Tsai Y-HL, Maron SB, McGann P, Nightingale KK, Wiedmann M, et al. (2011) Recombination and positive selection contributed to the evolution of
Listeria monocytogenes lineages III and IV, two distinct and well supported uncommon L. monocytogenes lineages. Infection, Genetics and Evolution 11: 1881-1890 doi:10.1016/j.meegid.2011.08.001:

Vanegas MC, Vasquez E, Martinez AJ, Rueda AM (2009) Detection of Listeria monocytogenes in raw whole milk for human consumption in Colombia by real-time PCR. Food Control 20: 430-432

Vera H, Ferro CJ, Triana LM (2006). Prevalencia de Listeria moncytogenes en derivados cárnicos cocidos para consumo directo analizados en el laboratorio de salud pública, Bogotá 1 de septiembre 2001- 31 agosto de 2004. 20p

Von Laer AE, de Lima AS, dos Santos Trindade P, Andriguetto C, Destro MT, et al. (2009) Characterization of Listeria monocytogenes isolated from a fresh mixed sausage processing line in Pelotas-RS by PFGE. Brazilian Journal of Microbiology 40: 574-582

Ward TJ, Evans P, Wiedmann M, Usgaard T, Roof SE, et al. (2010) Molecular and phenotypic characterization of Listeria monocytogenes from U.S. Department of Agriculture Food Safety and Inspection Service surveillance of ready-to-eat foods and processing facilities. Journal of Food Protection 73: 861-869

Warriner K, Namvar A (2009) What is the hysteria with Listeria? Trends in Food Science \& Technology 20: 245254

Williams SK, Roof S, Boyle EA, Burson D, Thippareddi $\mathrm{H}$, et al. (2011) Molecular ecology of Listeria monocytogenes and other Listeria species in small and very small ready-to-eat Meat processing plants. Journal of Food Protection 74: 63-77 doi:10.4315/0362-028X. JFP-10-097:

Yomayusa N, Suárez IC, Hernández P, Gaitán H, Altahona H, et al. (2008) Caracterización de un brote de infección por Acinetobacter baumannii en una unidad de cuidado crítico en Bogotá, Colombia. Infectio 12: 237-246

Zunabovic M, Domig KJ, Kneifel W (2011) Practical relevance of methodologies for detecting and tracing of Listeria monocytogenes in ready-to-eat foods and manufacture environments - A review. LWT - Food Science and Technology 44: 351-362 
Electroforesis en Gel de Campo Pulsado (PFGE) para la diferenciación molecular de Listeria monocytogenes

Resumen. En Colombia no es obligatoria la notificación de L. monocytogenes en alimentos, pero se vigilan los alimentos de alto riesgo. Clínicamente se reportan como microorganismo Gram-positivo sólo cuando causan meningitis. L. monocytogenes es un patógeno intracelular, transmitido por alimentos, letal para humanos y animales, que causa Listeriosis; enfermedad que genera varios brotes en el mundo, con pérdidas humanas y económicas. Pocos trabajos en Colombia han logrado identificar y serotipificar molecularmente los aislamientos, lo que sólo permite distribuir teóricamente los serotipos en linajes. Esta revisión se limita a mostrar características del patógeno, su importancia en salud pública y en la industria de alimentos, generalidades de la PFGECHEF; identificando el protocolo estandarizado de trabajo y las enzimas de restricción adecuadas para cortar el ADN. Se encontró que la combinación de enzimas $\mathrm{X} b a \mathrm{I}-A s c \mathrm{I}$, seguida de $A p a \mathrm{I}$ es la que ofrece mejores resultados en la diferenciación de los aislamientos; agrupándolos por linajes; mostrando variaciones intra-serotipo y que en varios países latinoamericanos se analizan los resultados a través de PulseNet, lo que garantiza la comparación de los patrones de PFGE en igualdad de condiciones.

Palabras clave: Tipificación molecular; linajes; serotipos; Listeria.
Electroforese em Gel de campo pulsado (PFGE) para a diferenciação molecular de Listeria monocytogenes

Resumo. Na Colômbia não há uma notificação compulsória de L. monocytogenes em alimentos, mas alimentos de alto risco são monitorados. Clinicamente, são relatados como organismos Gram-positivos apenas quando eles causam meningite. L. monocytogenes é um patógeno intracelular de origem alimentar, letal para seres humanos e animais, que causa a listeriose, que gera surtos em todo o mundo, com perdas humanas e econômicas. Poucos trabalhos na Colômbia identificaram e sorotipificaram molecularmente os isolados, que só permite a distribuição de sorotipos teoricamente em linhagens. Esta avaliação é limitada a mostrar características do patógeno, sua importância na saúde pública e na indústria de alimentos, e uma visão geral do PFGE-CHEF; identificar o protocolo-padrão de trabalho e enzimas de restrição apropriadas para cortar o ADN. Verificou-se que a combinação de enzimas XbaI$A s c \mathrm{I}$, seguido por $A p a \mathrm{I}$ representa a combinação de enzimas que ofereceu melhores resultados na diferenciação dos isolados, agrupando-a por linhagens, mostrando a variação intra-serotipo e que, em muitos países da América Latina, os resultados são analisados através PulseNet, que assegura a comparação de padrões de PFGE em igualdade de condições.

Palavras-chave: Tipagem molecular; linhagens; sorotipos; Listeria. 